\title{
A new outsourcing framework: A case study of educational institution activities
}

\author{
Mohammad Mahdavi Mazdeh" and Mohammad Reza Lotfollah Hamedani
}

Department of Industrial Engineering, Iran University of Science \& Technology, Tehran, Iran

\begin{tabular}{l}
\hline A R T I C L E I N F O \\
\hline Article history: \\
Received September 10, 2011 \\
Received in Revised form \\
October, 30, 2011 \\
Accepted 10 January 2012 \\
Available online \\
25 January 2012 \\
\hline Keywords: \\
Outsourcing \\
PMBOK \\
Educational activities \\
Outsourcing Methodology \\
\hline
\end{tabular}

\section{A B S T R A C T}

During the past two decades, there have been growing interests on reducing different activities using outsourcing activities. Outsourcing allows us to focus only on value added activities, which helps reduce the size of organizations. In this paper, we present a new framework based on PMBOK, which determines and ranks important activities for outsourcing. The proposed model of this paper is implemented for a real-world case study in educational system. We have distributed a questionnaire among some decision makers and asked them about their opinions on outsourcing activities on Likert scale. We have compared the relative importance of four major activities including educational activities, research and development, administration and services. The results indicate that general services are the most important activities, which are suitable for partnership followed by administration activities. Educational and research activities and development are in lower important activities.

(C) 2012 Growing Science Ltd. All rights reserved.

\section{Introduction}

During the past few years, there have been tremendous interests in reducing unnecessary tasks using outsourcing activities. Outsourcing plays an important role on increasing organizations' efficiencies by reducing the cost of products and services (Cullen et al., 2005). Gonzalez et al. (2006) presented a comprehensive review on information systems (IS) outsourcing. They analyzed the literature with the objective to determine the main topics, the methodologies most often used to the area of IS outsourcing. They also introduced some suggestions on improving research in this field and provided a review of articles about IS outsourcing.

Outsourcing also helps them cope with uncertain economic conditions since the number of permanent jobs reduces, significantly (Jennings, 1997). Specific tasks are concentrated in different smaller scale firms and they can handle activities more effectively (Mclvor, 2008). According to Quinn (1997), outsourcing has the befit of leveraging activities. Outsourcing could effectively increase the capability of organization when it is implemented through an appropriate strategy (Momme, 2002).

\footnotetext{
* Corresponding author. Tel: +9821 73225002

E-mail addresses: mazdeh@iust.ac.ir (M. Mahdavi Mazdeh)

(c) 2012 Growing Science Ltd. All rights reserved doi: $10.5267 /$ j.msl.2012.01.025
} 
Bustinza et al. (2010) performed an empirical study on the effect of outsourcing on service businesses. They found there was a relationship between outsourcing decisions and company performance articulated via the impact of outsourcing decisions on the firm's competitive capabilities. Horgos (2009) studied the importance of measurement differences for analyzing labor market effects of international outsourcing.

Mann et al. (2011) modeled the diffusion of IT outsourcing using announcements about IT outsourcing deals. They estimated a lognormal diffusion curve to examine whether IT outsourcing maintains a pure diffusion process or there are contagion impact involved. Their methodology studied the consequences of outsourcing events, especially contracts worth well more than US\$1 billion and evaluated the impact of various communication channels in the diffusion process of IT outsourcing by examining for the fit of the mixed influence model at the industry level. They also evaluated the consistency of evidence at two various levels of analysis and assessed two flexible diffusion models including the Gompertz and Weibull models. The results indicated that the diffusion patterns of IT outsourcing would not seem to be lognormal, recommending that IT outsourcing does not follow a complete diffusion process.

Whitten et al. (2010) discussed that the major IT outsourcing contracts were mostly discontinued in favor of other choices such as returning to in-house development or switching to another vendor. Switching expenditures are experienced when ending a business relationship and securing a choice. They tried to understand whether switching costs matter substantially in the strategic choice to maintain outsourcing or switch vendors. They performed a field survey for each of these cost components and suggested that customer organizations preferred outsourcing continuation most and backsourcing least when their switching costs were high.

The proposed study of this paper tries to indentify different activities associated with educational organizations. The proposed study of this paper first presents details of our framework in section 2, and section 3 explains details of finding and concluding remarks are given in section 4 to summarize the contribution of the paper.

\section{The proposed outsourcing framework}

The proposed study of this paper attempts to use the method proposed by Cullen et al. (2005) with adaptation of PMBOK project (2000). The proposed study of this paper has four stages including decision-making, planning, execution and re-evaluation. The first stage itself includes objectives, activities, financial plan and risk associated with outsourcing activities. The second stage is associated with the selection of appropriate supplier and ranking them. The third phase of the proposed method includes execution activities, which are as follows,

1. Preparing an appropriate culture within the organization,

2. Human resource management,

3. Designing a suitable team project,

4. Control and management,

5. Planning for activity assignment,

6. Supplier management relationship,

7. Quality assessment,

8. Trouble shooting and managing conflicts. 
Finally, occasionally, outsourcing activities must be re-evaluated through to reduce any conflicting issues happening in the last stage of the proposed model. The close loop of the proposed model helps reduce any barriers. Fig. 1 shows details of the our proposed methodology.

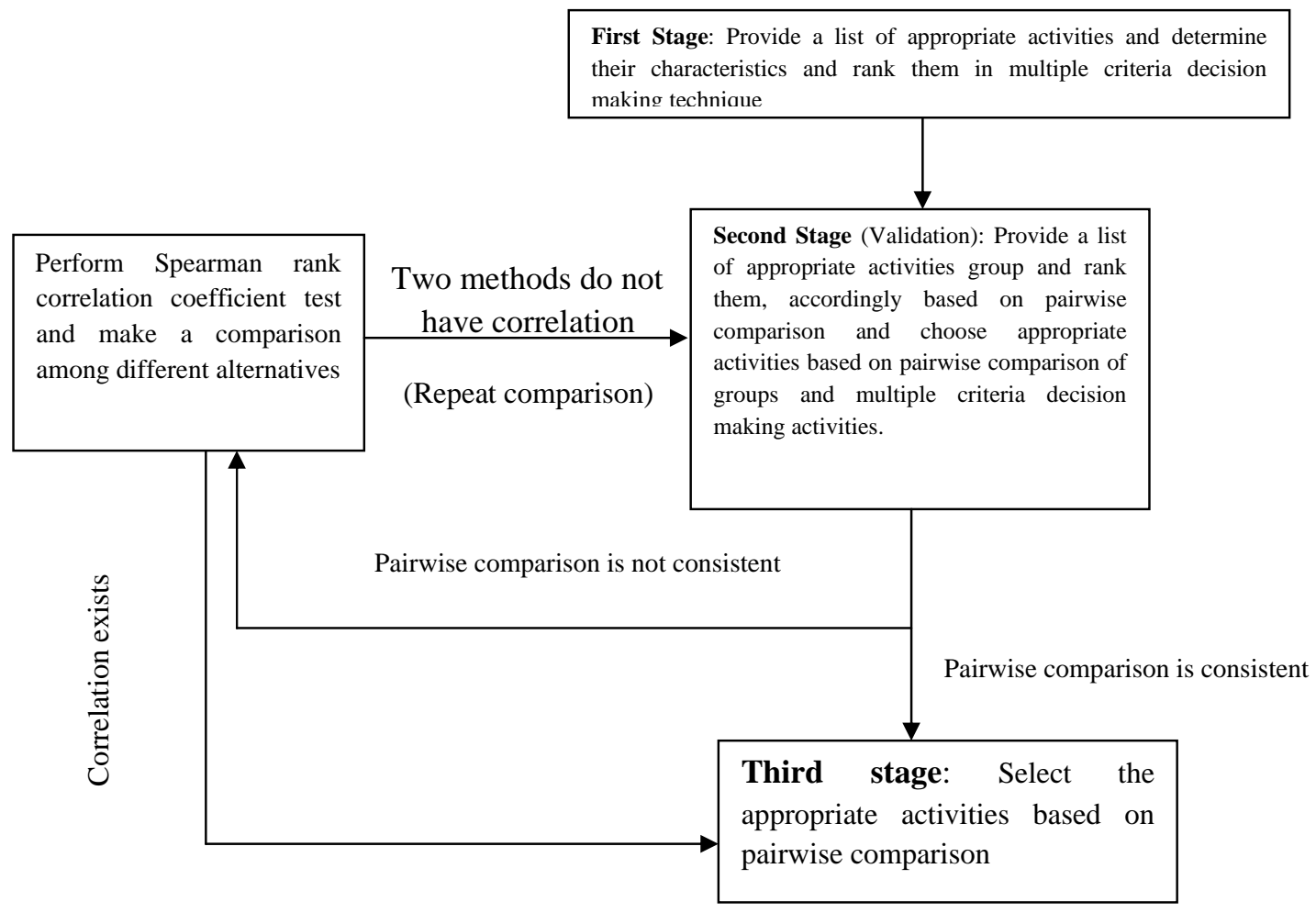

\section{Case study}

Fig. 1. The framework of the proposed model

The proposed study of this paper has been implemented for a real-world case study of a governmental university located in Iran. The questions are in Likert based from one to five shown in Table 1.

\section{Table 1}

The results of the survey

\begin{tabular}{|c|c|c|c|}
\hline Educational activities & Mean & Administration & Mean \\
\hline General courses & 3 & Green space maintenance & 4.75 \\
\hline Basic sciences & 2.5 & Food services & 4.75 \\
\hline Undergraduate courses & 1 & Copy centers & 4.25 \\
\hline Graduate courses & 1.5 & Book stores & 4.25 \\
\hline Physical labs & 2.25 & University web maintenance & 2 \\
\hline Graduate thesis & 1.5 & Custodian services & 4.75 \\
\hline Seminars & 1 & University equipment maintenance & 4.75 \\
\hline \multirow[t]{2}{*}{ Elective activities } & \multirow[t]{2}{*}{3} & Security & 1.75 \\
\hline & & Transportation & 4.75 \\
\hline Research \& development & Mean & Phone center & 2.25 \\
\hline Research centers & 1.25 & Computer center & 2.5 \\
\hline Conferences & 2.5 & IT center & 3.5 \\
\hline Research projects & 1.5 & Central library & 2 \\
\hline \multirow[t]{2}{*}{ Incubators and growth centers } & \multirow[t]{2}{*}{1.75} & Student residency & 2.75 \\
\hline & & E-service training contents & 2.25 \\
\hline General services & Mean & Consultation services & 3 \\
\hline Mail services & 2 & Publication center & 3.25 \\
\hline General teaching services & 2 & Student society services & 3.5 \\
\hline Human resource training center & 3 & Broacher and guidelines & 4.25 \\
\hline Payment services & 2.25 & Examination centers & 1.75 \\
\hline
\end{tabular}


As we can observe from the results of Table 1, teaching general courses and elective courses are the most important item for outsourcing, followed by basic courses and running physical labs. In terms of research activities, organization and execution of different conferences is the most favorable activity for outsourcing. Human resource training activities are among the most important item in general service activities, which can be considered for outsourcing.

In addition, there are many activities in administration level, which could be considered for outsourcing. The mean scores for these items are relatively high and they are close to either completely agree or agree. The most important items include green space maintenance, food services, custodian services, university equipment maintenance, transportation facilities and student residency. Our decision makers have strongly recommended to outsource these activities and they also agreed for outsourcing activities such as copy center, book stores and preparing broacher and guidelines.

We have also used paired comparison to find the relative importance of each components of four items and the results are summarized in Table 2.

Table 2

The results of the implementation paired comparison

\begin{tabular}{lccccc}
\hline Normalized matrix & Education & $\begin{array}{c}\text { Research and } \\
\text { development }\end{array}$ & Administration & Services & Mean \\
\hline Education & 0.07 & 0.11 & 0.07 & 0.05 & 0.08 \\
Research and development & 0.04 & 0.06 & 0.08 & 0.04 & 0.05 \\
Administration & 0.56 & 0.43 & 0.58 & 0.066 & 0.55 \\
Services & 0.33 & 0.40 & 0.27 & 0.25 & 0.32 \\
\hline Sum & 1 & 1 & 1 & 1 & 1 \\
\hline
\end{tabular}

Again, as we can observe from the results of Table 2, administration and general services are the most important activities in our survey. While these items have received 87 percents of the relative importance on behalf of the people who participated in our survey, educational items as well as research and development activities are not highly recommended for outsourcing activities. This is consistent with university mission, which are based on research and education.

If we look at other successful outsourcing activities performed in many well known, high rank universities, we will find out that these schools do their best to hire university professors with high qualification background. The primary objective of the high-level universities is to develop leading edge technology research activities along with training students. In such environment, the core coincidence of university activities is to focus on creativity and innovation, which are the basis of future success.

During the past few years, we have seen many high tech business units such as Google, Ebay, etc. The idea of all these well known business units has emerged from the North American universities. The universities tried to focus on absorbing highly motivated people and concentrated their efforts on educating these people.

Note that the consistency ratio for our calculation was 0.587 , which was well more than the level of 0.1 and we needed to repeat our pairwise comparison. However, the proposed model of this paper uses Spearman rank correlation coefficient test (Spearman, 1904; Piantadosi et al., 2007) to repeat the pairwise comparison only when the assumption of having the same rank is rejected. The null hypothesis is that there is no correlation between two groups and the alternative hypothesis is that 
there is a correlation between them. The results of test yields 0.047 for the error type one, which is less than 0.05. Therefore, we can reject the hypothesis of having independent groups and two groups have positive correlations. In stage 3 of Fig. 1 we can choose between outsourcing or signing contract.

According to the results of Table 3, neither teaching nor research \& development is suggested by university officials for outsourcing. However, there are some exceptions such as teaching general courses, which could be assigned as outsourcing.

\section{Table 3}

The results of pairwise comparison between different alternatives based on either outsourcing or signing a contract

\begin{tabular}{ccccc}
\hline Normalized matrix & Education & Research and development & Administration & Services \\
\hline $\begin{array}{c}\text { The relative importance for either } \\
\text { outsourcing to signing a contract }\end{array}$ & 0.67 & 0.67 & 0.75 & 0.85 \\
\hline Type & Outsourcing & Outsourcing & Contract & Contract \\
\hline
\end{tabular}

In case of administration and general services, the results of Table 3 recommend to assign some of the tasks through a contract to other organizations. According to Table 3, general service activities including mail delivery services, general teaching services, human resource training and payment services are among the most important activities, which must be considered for outsourcing. Administration activities are the second most important items including several factors such as green space maintenance, food services, custodian services, university equipment maintenance, transportation facilities and student residency, etc.

\section{Conclusion}

In this paper, we have presented a new method to rank different activities, which must be considered for outsourcing. The proposed model of this paper gathers people' feedback on various items based on Likert scale. The method also prioritizes the activities using pairwise comparison to determine the most important activities for outsourcing. The proposed model of this paper has been implemented for a real-world case study of governmental university and the results of our survey have indicated that administration tasks are among the most suitable activities for outsourcing purposes. Some of the most important items in administration level are green space maintenance, food services, custodian services, university equipment maintenance, transportation facilities and student residency, etc. There are also general activities, which are considered as the second most important activities and human resource training activities are among the most important item in general service activities, which can be considered for outsourcing.

\section{Acknowledgment}

The authors would like to thank the officials of the Iran University of Science and Technology for their support on providing necessary information on this research work.

\section{References}

Bustinza, O.F., Arias-Aranda, D., \& Gutierrez-Gutierrez, L. (2010). Outsourcing, competitive capabilities and performance: an empirical study in service firms. International Journal of Production Economics, 126(2), 276-288. 
Cullen, S., Seddon, P. \& Willcocks, L. (2005). Managing outsourcing: The life cycle imperative. MIS Quarterly Executive, 4(1), 229-246.

Gonzalez, R., Gasco, J., \& Llopis, J. (2006). Information systems outsourcing: A literature analysis. Information \& Management, 43(7), 821-834.

Horgos, D. (2009). Labor market effects of international outsourcing: How measurement matters. International Review of Economics \& Finance, 18(4), 611-623.

Jennings, D. (1997). Strategic guidelines for outsourcing decisions. Strategic Change, 6(2), 85-95.

Mann, A., Kauffman, R.J., Han, K., \& Nault, B.R. (2011). Are there contagion effects in information technology and business process outsourcing?. Decision Support Systems, 51(4), 864-874.

Mclvor, R. (2008). What is the right outsourcing strategy for your process?. European Management Journal, 26, 24-34.

Momme, J. (2002). Framework for outsourcing manufacturing: strategic and operational implications. Computers in Industry, 49(1), 59-75.

PMBOK:Project Management Body Of Knowledge. (2000). Guide. 2000 edition, The Project Management Institute, Inc.(PMI®).

Piantadosi, J., Howlett, P., Boland, J. (2007). Matching the grade correlation coefficient using a copula with maximum disorder. Journal of Industrial and Management Optimization, 3 (2), 305312.

Quinn, J. B. (1999) Strategic outsourcing: Leveraging knowledge capabilities. Sloan Management Review, 40(4), 9-21.

Spearman, C. (1904). The proof and measurement of association between two things. American Journal of Psychology, 15, 72-101

Whitten, D., Chakrabarty, S., \& Wakefield, R. (2010). The strategic choice to continue outsourcing, switch vendors, or backsource: Do switching costs matter?. Information \& Management, 47(3), 167-175. 